\title{
Experimental Investigation on Bead Geometry Parameter and Mechanical Property of Part Fabricated by Wire Arc Additive Manufacturing
}

DOI:10.36909/jer.ICMMMM.15643

\author{
Soundrapanidan E*, Vivekkumar P, Senthilkumar G \\ Department of Mechanical Engineering, Bannari Amman Institute of Technology, \\ Sathyamangalam, Erode, Tamilnadu, India. \\ * Corresponding Author: soundrapandian@ bitsathy.ac.in
}

\begin{abstract}
In additive manufacturing process, wire arc additive manufacturing process (WAAM) is a technique which can produce a metal 3D printed part. In Industries product are produced by wasting one third of its material, from this process time consumption and material wastage is more comparing in Subtractive Manufacturing over Additive Manufacturing. Additive Manufacturing stepped from 1925 in manufacturing industry and it has gained its remarkable growth in past few decades, as of now metal 3D oriented parts have come to play a major role in aerospace industry. This research work focused on Gas Metal Arc Welding (GMAW) welding. It has high deposition rate, ultimate build volume and good structural integrity compare with other additive manufacturing process. MACH3 controller is used to control the welding torch motion for addition of material by 3 axis movement (X, Y and Z). To identify the correct parameters for metal part we have done numbers of samples by changing values in the MIG machine from that we finalize the three parameters through visualizes on the printed materials after that a wall like structure is built and post processing like cutting the materials from base plate, grinding the uneven surface on printed materials. The printed materials are ready for material testing like bead geometry analysis of various parameter and tensile testing to identify the printed material strength, elongation, stress and strain.
\end{abstract}

Keywords: Additive Manufacturing; Metal Inert Gas Welding; Gas Metal Arc Welding (GMAW);Parameters; Bead geometry; Tensile Test. 


\section{INTRODUCTION}

In hybrid manufacturing metallic layers are built by weld deposition. The beads are formed by depositing multi weld beads overlapped on one another. In order to enhance the surface quality and dimensional accuracy the weld torch is integrated with a computer numerical controlled machine [1]. The wire arc additive manufacturing is a technique used to manufacture complex shaped part. Samples are prepared by controlling parameters such as voltage, ampere, wire feed and shielding gas to improve bead formation [2]. Microstructure of aluminum wire was investigated to reduce the gas porosity and hot cracking. The porosity in aluminium weld beads depends on the cleaning of support plate, wire surface quality, torch angle and polarity [3]. The important parameter in wire arc additive manufacturing of Inconel 625 on EN 8 steel are heating and cooling of bead geometry. As the travel speed increases the cooling rate increases, but when the applied current increased the cooling rate decreased as the energy input increases [4]. The evaluation of properties and microstructure of aluminum alloy using WAAM process in comparison with other metal additive manufacturing process. The microstructure evaluation on heat affected zone, crack, porosity and micro hardness its evident that WAAM process is better than other metal additive process [5]. A development in microstructural in the granular columnar structure in copper based components fabricated by short circuiting method was observed. The grain arranged in a well manner compared with pulse mode on polishing the samples with different grades of emery paper followed by diamond polishing [6]. There were several mechanisms for porosity nucleation in aluminum. The critical feature of wire that influence porosity formation is the surface finish. The notches create trap sites for contamination and the surface area of a rough surface is higher, thus increases the hydrogen content which would increase the porosity [7]. The wire arc additive manufacturing process is suitable for manufacturing large and complex parts. In the horizontal specimens the upper layer and middle layer shows higher tensile strength were the mechanical properties seems to be anisotropic. The mechanical properties became isotropic after annealing the sample [8]. The cost model and sensitivity analysis on wire arc additive manufacturing identifies that the indirect cost is the key cost driver. The WAAM process has activities such as substrate preparation, deposition, heat treatment, machining, and inspection [9]. The microstructure on WAAM process shows uncontrolled grain size during the process which induce tensile residual stress. The grain refinement can be achieved by surface treatment such as multiple laser shock penning where a pulsed laser is applied on metallic component to reduce the compressive residual stress [10]. The mechanical properties such as hardness and tensile are increased by controlling the arc travel speed. The component is manufactured using CMT technique with $1.2 \mathrm{~mm}$ wire diameter of Inconel 625 material. The torch speed and heat input is controlled by selecting constant value for wire feed, voltage and current [11]. Two separate filler materials into a single weld pool allows for functionally gradient material based on twin wire deposition. The factors such as wire speed, torch speed and filler content were plays an important role in affecting composition of deposited volume [12]. To attain or develop large production scale on the aluminium material in synergetic mode of operation. The mechanical property in a stress and strain curve and tested micro hardness for aluminum material. The material was tested by controlling current, voltage, wire feed and travel speed to deposit single bead deposition and block deposition [13]. The effect of building techniques such as oscillation, parallel and weaving on bead form were investigated for surface finish, lack of fusion problem. As a result of the investigation WAAM process could be used to make maraging steel material [14]. In the WAAM process the deposition rate of aluminum, titanium and steel material were tested. In order to get micro structural benefits high pressure interposes rolling is used [15]. The free form technique with a low buy fly ratio for large component manufacturing. A rectangular prototype of Inconel $625 \mathrm{slab}$ alloy is fabricated where the alloy had a columnar dendritic structure. It was evident 
that deposited alloy has higher tensile strength than solution annealed alloy [16]. The effect of metal transfer characteristic of micro structure formation at interfacial layer is analyzed for functionally graded material (FGM) which have structural property that vary along their volume. This FGM has extensive application in marine industry [17]. A multibead deposition model was predicted by using parameters such as filler diameter, filler wire speed, welding torch speed and distance between consecutive beads. Then single bead experiment was carried by changing the value of wire speed and current parameter and they predicted to multibead deposition model to layer thickness and yield as the function of the three process parameters [18]. The heat input and travel speed is compared to understand the mechanical property of materials. The values of voltage and wire feedrate are varied to get various heat input samples [19]. A hybrid system was developed by combining gas metal arc welding (GMAW) and milling processes. The voltage and current intensity is considered as fundamental parameter and the relationship between the intensity and voltage with wire feed is studied [20].

\section{Gas Metal Arc welding (GMAW)}

\section{COMPONENTS AND MATERIALS}

MIG welding machine $280 \mathrm{~S}$ model by WIM Malaysia produced in 2010, which operates in four different course voltages and eight different fine voltages. Weld wire feed rates can be adjusted to nine different levels, allowing for three different weld operations: continuous, spot, and stitch. Table 1 shows the machine specification of $280 \mathrm{~S}$ model WIM Malaysia.

Table 1. Specification of MIG machine

\begin{tabular}{|l|l|}
\hline Main supply & 3 -phase $50 / 60 \mathrm{~Hz}$ \\
\hline Voltage & $380 \mathrm{~V}-415 \mathrm{~V}$ \\
\hline Max input current & $24 \mathrm{~A}$ \\
\hline Output rating & $280 \mathrm{~A} / 28 \mathrm{~V}$ \\
\hline Open circuit voltage & $19 \mathrm{~V}-39 \mathrm{~V}$ \\
\hline Welding range 50-210A & $4-0 \mathrm{~A}-280 \mathrm{~A}$ \\
\hline Wire feeding speed & $1-20 \mathrm{~m} / \mathrm{min}$ \\
\hline Degree of protection & IPS21 \\
\hline Insulation class & H180OC \\
\hline
\end{tabular}

\section{Shielding Gas}

The primary purpose of shielding gas is to prevent oxygen, nitrogen, and hydrogen from entering the molten weld tank. Porosity and excessive spatter will result from these elements reacting with the weld pool. Shielding gas affects the welding profiles and make welding good and slag free by creating a sound environment for the welding operation, which will also increase the product quality of the welding. Carbon Dioxide $\left(\mathrm{CO}_{2}\right)$ is commonly used in mig welding machine.

\section{Weld Wire}

ER70s-6 is of diameter of $0.08 \mathrm{~mm} \varnothing$ is a wire with a higher concentration of deoxidizers for welding steels. Compared to other carbon steel cables, (Mn \& Si) This wire can be used to weld steels that have a mild amount of scale or rust. Table 2 shows the chemical composition of the ER70S-6. Figure 1 shows the mig wire fitted with mig welding machine.

Table 2. weld wire ER70s-6 chemical composition

\begin{tabular}{|c|c|c|c|c|c|c|c|c|}
\hline $\mathrm{C}$ & $\mathrm{Mn}$ & $\mathrm{Si}$ & $\mathrm{Cr}$ & $\mathrm{Mo}$ & $\mathrm{V}$ & $\mathrm{P}$ & $\mathrm{S}$ & $\mathrm{Cu}$ \\
\hline 0.08 & 1.45 & 0.98 & 0.05 & 0.01 & 0.012 & 0.010 & 0.010 & 0.04 \\
\hline
\end{tabular}




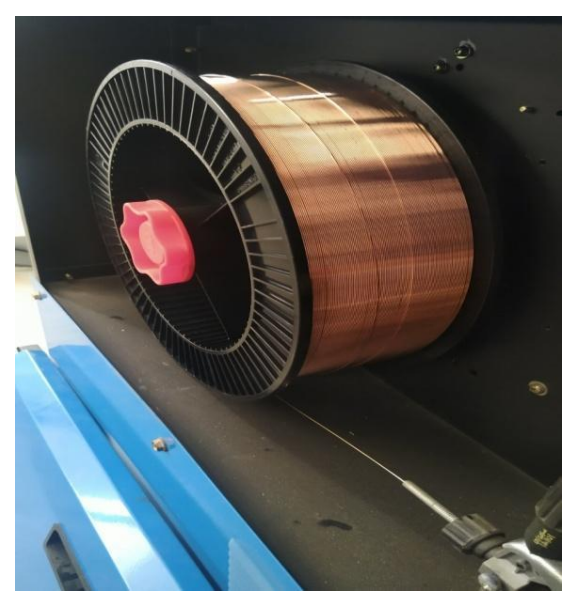

Figure 1. Weld wire fitted with MIG

\section{Parameter Selection}

The mechanical properties of the part produced by welding are depends entirely on the selection of welding parameter and shielding gas used. For producing good product, we should select the good parameters only. By changing the parameter, we can change the quality of fabrication of the product, so we should choose wisely the parameters before the fabrication of the product. Course voltage, fine voltage, and feed rate were the parameters chosen for research. Table 2 shows the testing of sample at different parameters.

Table 2. Welding parameters

\begin{tabular}{|c|c|c|c|c|}
\hline S.NO & $\begin{array}{c}\text { VOLTAGE } \\
\text { (Coarse) }\end{array}$ & $\begin{array}{c}\text { VOLTAGE } \\
\text { (FINE) }\end{array}$ & TRACK SPEED & FEED RATE \\
\hline 1 & 4 & 1 & 3 & 1 \\
\hline 2 & 4 & 2 & 3 & 1 \\
\hline 3 & 4 & 3 & 3 & 1 \\
\hline 4 & 4 & 4 & 3 & 1 \\
\hline 5 & 4 & 5 & 3 & 1 \\
\hline 6 & 4 & 6 & 3 & 1 \\
\hline 7 & 4 & 7 & 3 & 1 \\
\hline 8 & 4 & 8 & 3 & 2 \\
\hline 9 & 3 & 1 & 3 & 2 \\
\hline 10 & 3 & 2 & 3 & 2 \\
\hline 11 & 3 & 3 & 3 & 2 \\
\hline 12 & 3 & 4 & 3 & 2 \\
\hline 13 & 3 & 5 & 3 & 2 \\
\hline 14 & 3 & 6 & 3 & 3 \\
\hline 15 & 3 & 7 & 3 & 3 \\
\hline 16 & 3 & 8 & 3 & 3 \\
\hline 17 & 4 & 1 & 3 & 3 \\
\hline 18 & 4 & 2 & 3 & 3 \\
\hline 19 & 4 & 3 & 3 & 3 \\
\hline 20 & 4 & 4 & 3 & 3 \\
\hline 21 & 4 & 5 & 3 & 3 \\
\hline 22 & 4 & 6 & 3 & 3 \\
\hline 23 & 4 & 7 & 3 & 3 \\
\hline 24 & 4 & 1 & 3 & 3 \\
\hline 25 & 4 & & 3 & 3 \\
\hline
\end{tabular}




\begin{tabular}{|l|l|l|l|l|}
\hline 26 & 4 & 2 & 3 & 4 \\
\hline 27 & 4 & 3 & 3 & 4 \\
\hline 28 & 4 & 4 & 3 & 4 \\
\hline 29 & 4 & 5 & 3 & 4 \\
\hline 30 & 4 & 6 & 3 & 4 \\
\hline 31 & 4 & 7 & 3 & 4 \\
\hline 32 & 4 & 8 & 3 & 4 \\
\hline
\end{tabular}

The sample welding for all 32 parameters as shown in table 2 were performed used the weld machine. Figure 2 shows the sample welding using weld track setup.

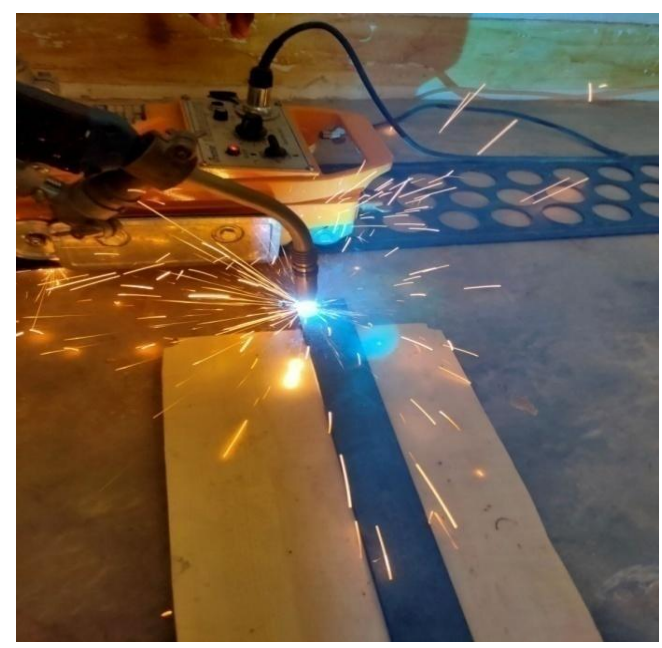

(a)

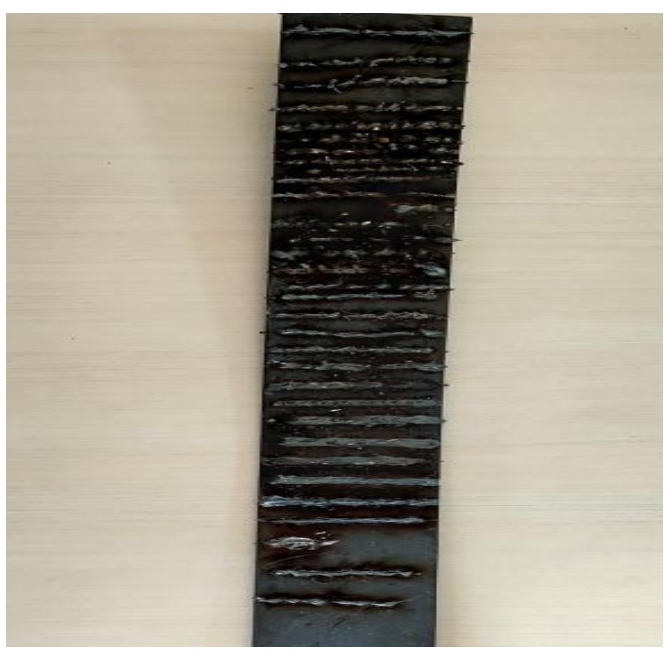

(b)

Figure 2. Weld bead samples

After performing single bead weld, from the array of weld beads it is concluded that feed rate of four and coarse voltage of four and fine voltage of five (29), six (30), seven (31), eight (32) are given good result. As shown in figure 3 from the single weld bead the coarse voltage four (4), fine voltage six (6) and feed rate three (3) were selected for building the wall like structure.

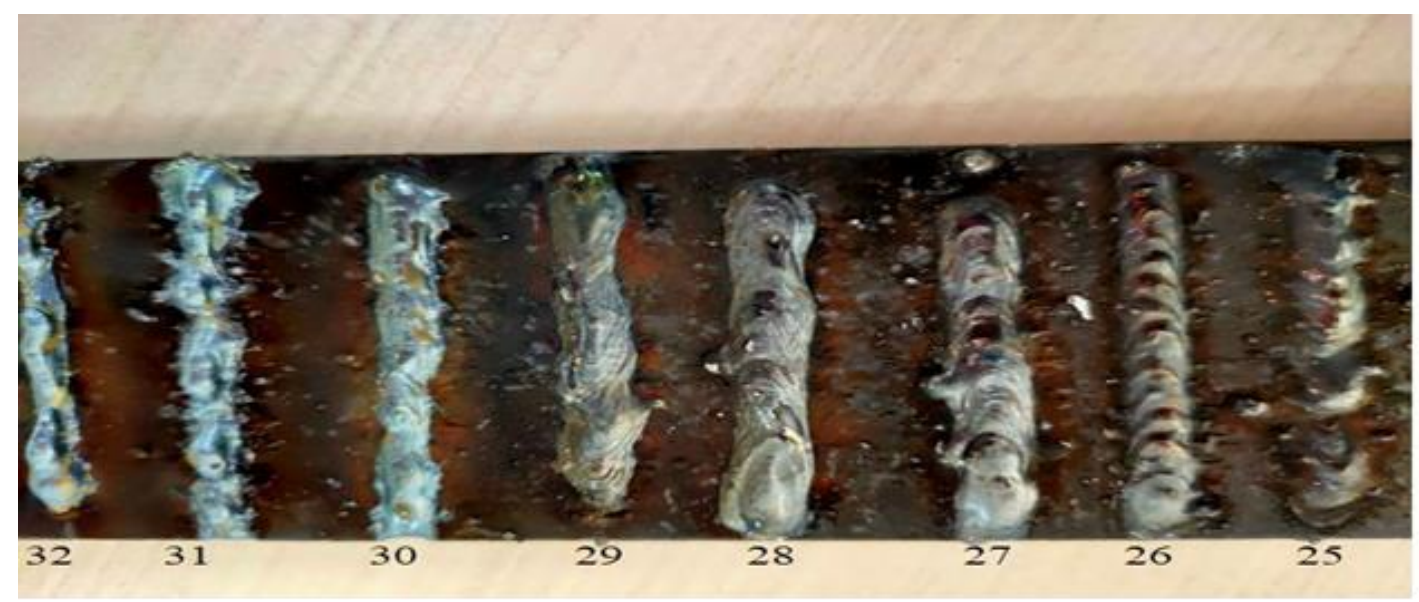

Figure 3. Good bead structure selected from sample weld plate

\section{EXPERIMENTAL PROCEDURE}

Wire arc additive manufacturing process consists of welding machine, CNC machine, weld wire, nozzle and shielding gas. The weld wire used for the fabrication is ER70S-6 which is 
mild steel wild wire. The CNC machine runs using mach3 software and controlled by mach3 controller, which help to convert the $\mathrm{G}$ code for the fabrication process digital signal for the $\mathrm{CNC}$ operation. Nozzle used is of $0.8 \mathrm{~mm}$ diameter and made of brass. $\mathrm{CO} 2$ is used as shielding gas for good welding. The base material use was mild steel, the gap between the nozzle and the base plate is $15 \mathrm{~mm}$ to have adequate space for welding, which will help to reduce the overlap. The CNC programs for welding of 25 layers are written and imported to mach3 software. The MIG welding specifications are set according to the readings in table 3 . The welding operation is done in single direction and in perpendicular angle there were time gap 15 seconds for each layer which will allow good depositing of the wed material and helps in the cooling process. During all this process the $\mathrm{CO} 2$ gas is used as shielding gas, which will help to improve the quality of welding.

Table 3. Selected parameters for fabrication

\begin{tabular}{|c|c|c|c|c|}
\hline S.No & Voltage (coarse) & Voltage (fine) & $\begin{array}{c}\text { Feed in CNC Machine } \\
(\mathbf{m m} / \mathbf{s})\end{array}$ & $\begin{array}{c}\text { Wire Feed Rate } \\
(\mathbf{m m} / \mathbf{s})\end{array}$ \\
\hline 1 & 4 & 6 & 30 & 4 \\
\hline
\end{tabular}

The figure 4 shows the wall of dimension $120 \times 10 \times 100 \mathrm{~mm}$ fabricated by weld deposition of weld wire ER70S-6 for the parameter values shown in table 3.

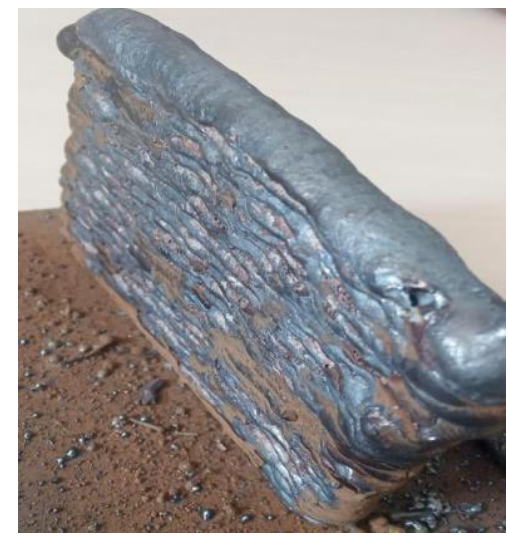

Figure 4. Fabricated weld wall of dimension 120 x 10 x $100 \mathrm{~mm}$

\section{POST-PROCESSING}

A hand cutter machine was used to machine all specimens for mechanical properties examination, which were then ground and polished as shown in figure 5.

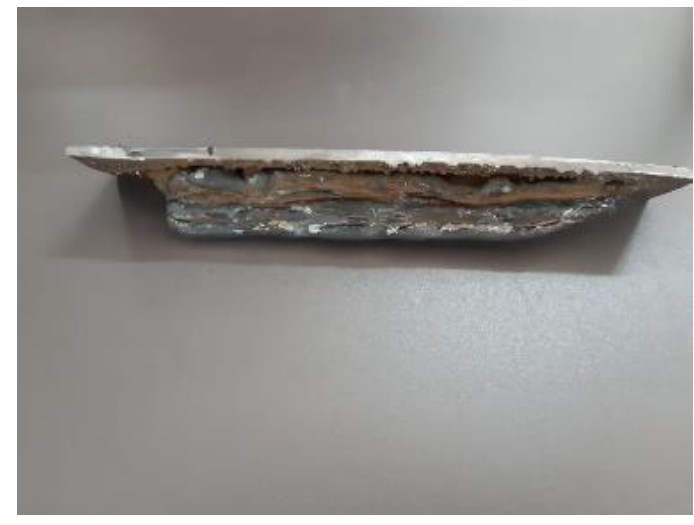

(a)

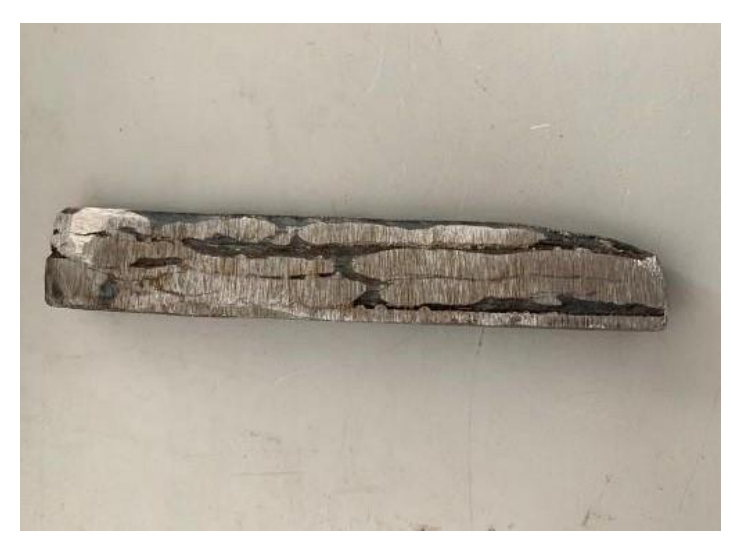

(b) 
Figure 5. Preparation of sample for testing

\section{RESULTS AND DISCUSSION}

\section{Tensile Test}

Tensile test is taken out for the specimen to study their breaking nature and elongation properties. FIE Universal Tensile tester as shown in figure 6 was used in the process of testing. The specimens were fixed between the upper and lower jaws of the machine. Machine parameters are pre-set with its respective FIE software in machine for the test to be taken. As the test process starts, the upper jaw moves upward while the lower jaw remains constant. At certain point the specimen breaks, indicating its max breaking capacity. The results are all obtained in the software and graphs are also generated for the same and the results can be customized based on the requirement with graph plotting too. The figure 7 shows the tensile test specimen before the test.

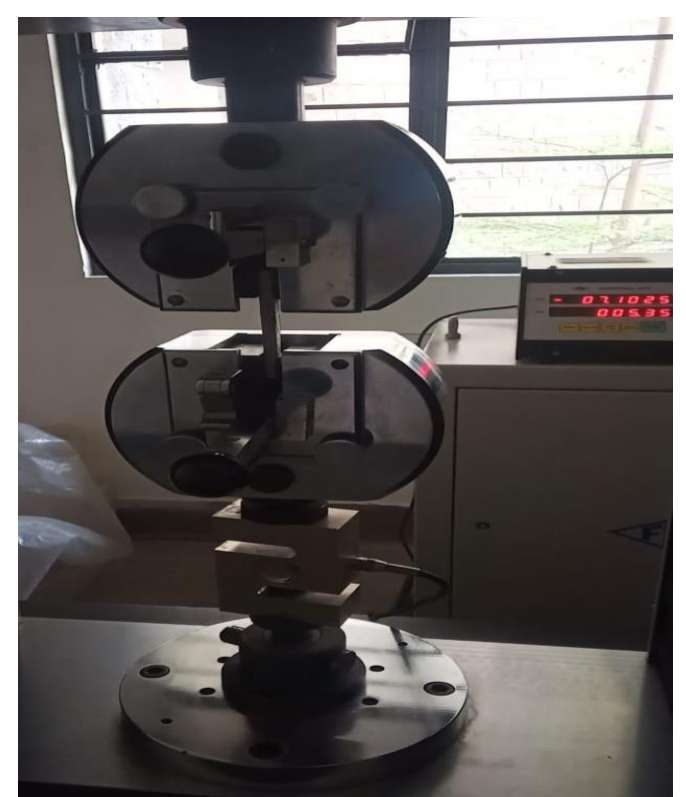

(a)

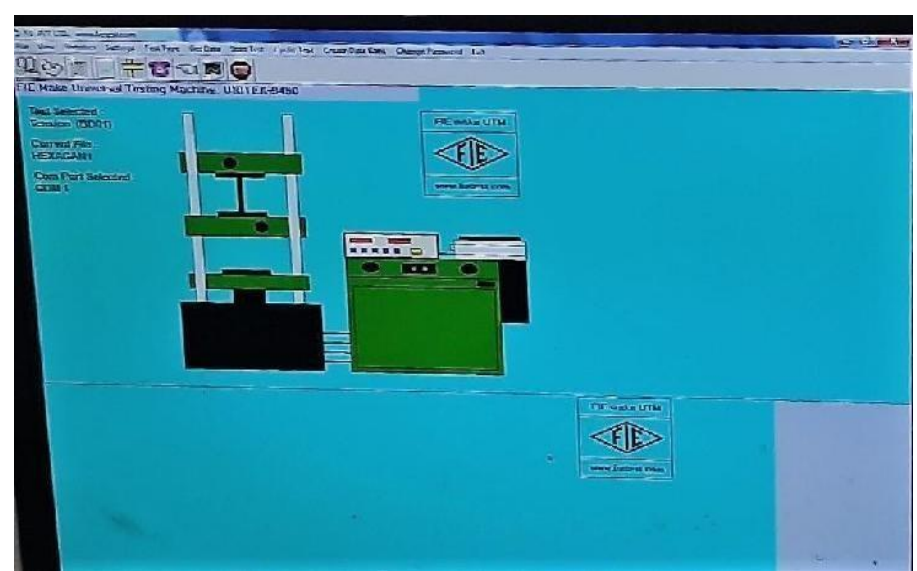

(b)

Figure 6. FIE Tensile Testing Machine setup

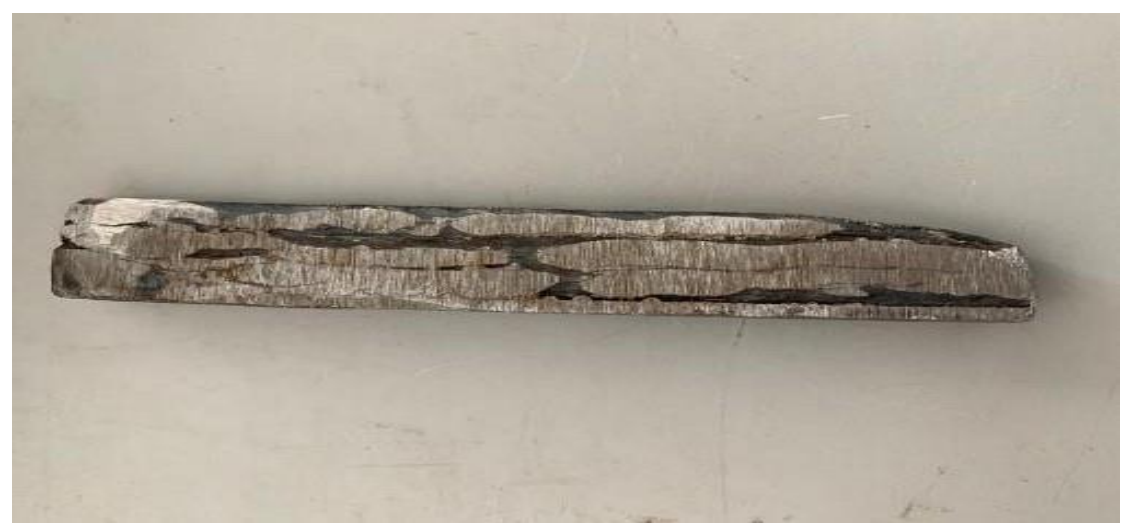

Figure 7. Tensile Testing Specimen

\section{Tensile Result for Specimen 1}

This specimen is made with feed rate of $2 \mathrm{~mm}$ per minute, voltage of $4 \mathrm{v}$ and precision voltage of $5 \mathrm{v}$ and current range at 65 to 85 amps. After the post processing the material is made into $10 \mathrm{~mm}$ length and thickness of $10 \mathrm{~mm}$ as per the testing standard of the machine. It is clamped into machine in the jaws and the load is given to the material. The graph on load and 
displacement are obtained as shown in figure 8 for specimen 1 is obtained. The stress and displacement are obtained in the form of graph as shown in figure 9 and also stress vs strain curve graph is obtained as shown in figure 10.

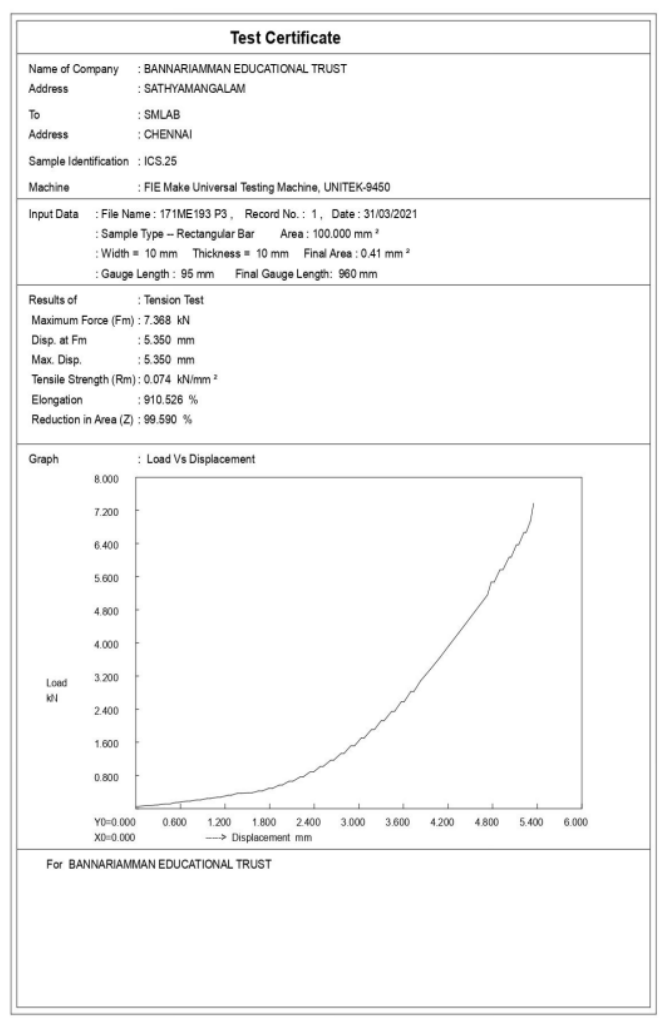

(a)

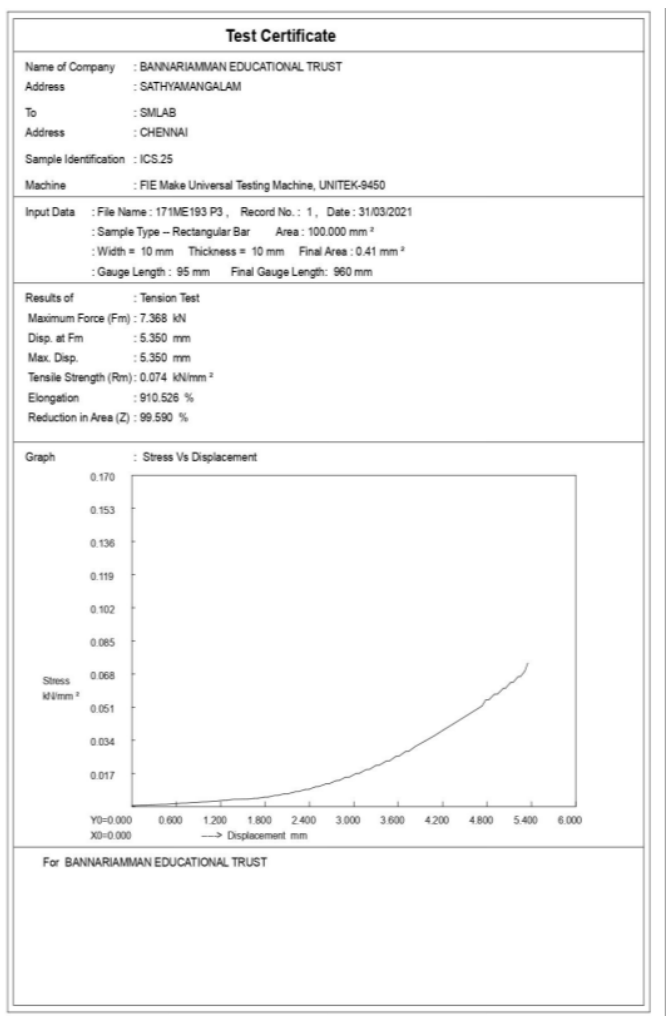

(b)

Figure 8. (a) Load vs Displacement graph for specimen 1, (b) Stress vs Displacement graph for specimen 1 


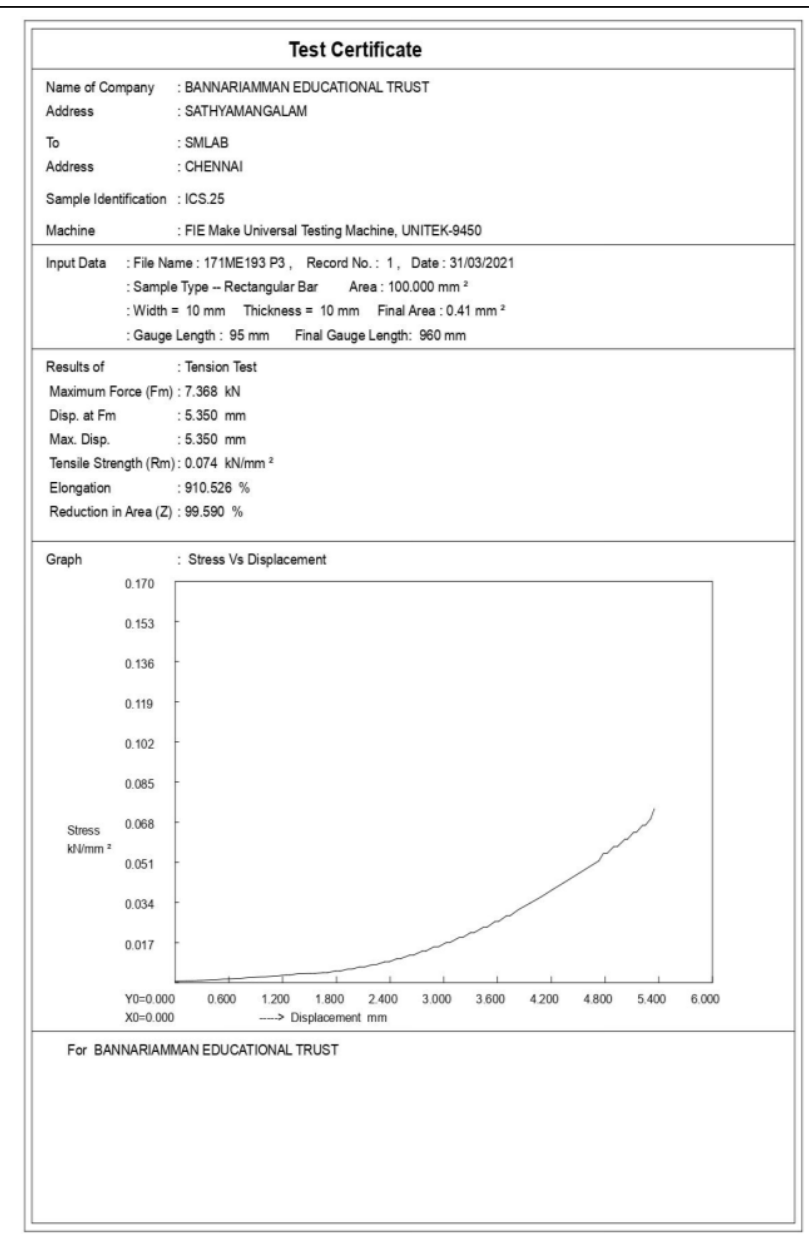

Figure 9. Stress vs Strain graph for specimen 1

The specimen is made in rectangular cross section structure after testing it have the maximum load or force of $7.368 \mathrm{kN}$, maximum displacement of $5.350 \mathrm{~mm}$, Tensile Strength of $0.074 \mathrm{kN} / \mathrm{mm} 2$ and elongation percentage of $910.526 \%$. The final area obtained is $0.41 \mathrm{~mm} 2$ and final gauge length is $960 \mathrm{~mm}$.

\section{Tensile Test Result for Specimen 2}

This specimen is made with feed rate of $3.20 \mathrm{~mm}$ per minute, voltage of $4 \mathrm{v}$ and precision voltage of $6 \mathrm{v}$ and current range at 90 to 110 amps. After the post processing the material is made into $10 \mathrm{~mm}$ length and thickness of $10 \mathrm{~mm}$ as per the testing standard of the machine. It is clamped into machine in the jaws and the load is given to the material. The load and displacement are carried out the graph as shown in the figure 11 (a) for specimen 2 is obtained. The stress and displacement are obtained as shown in the figure 11 (b) and also stress vs strain curve graph is obtained as shown in the figure 12. 


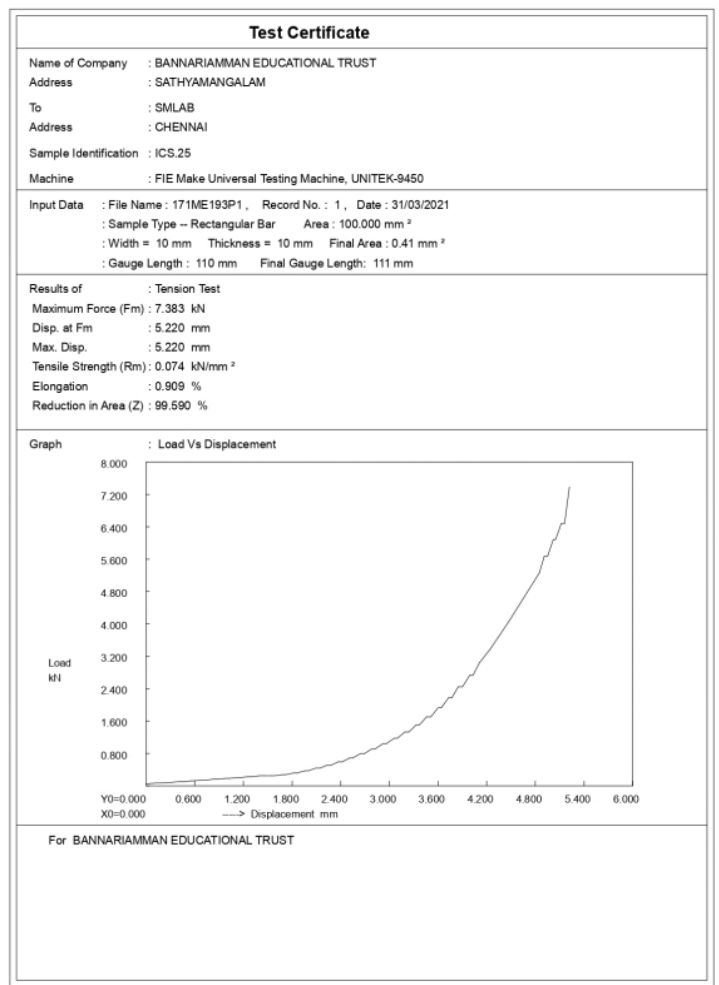

(a)

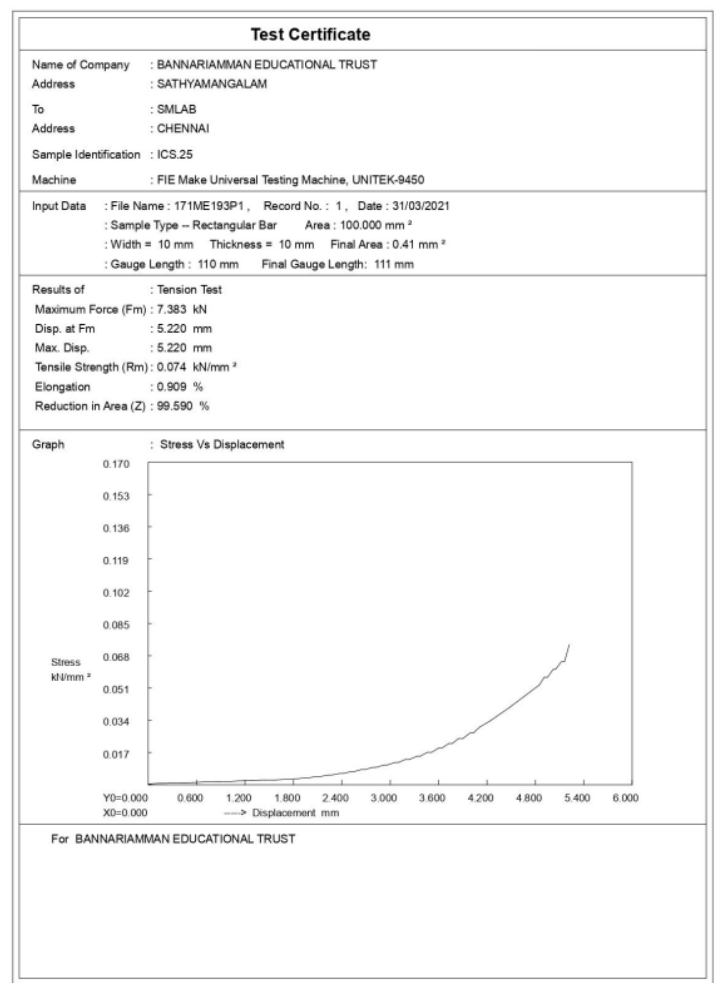

(b)

Figure 11. (a) Load vs Displacement graph for specimen 2, (b) Stress vs Displacement graph for specimen 2

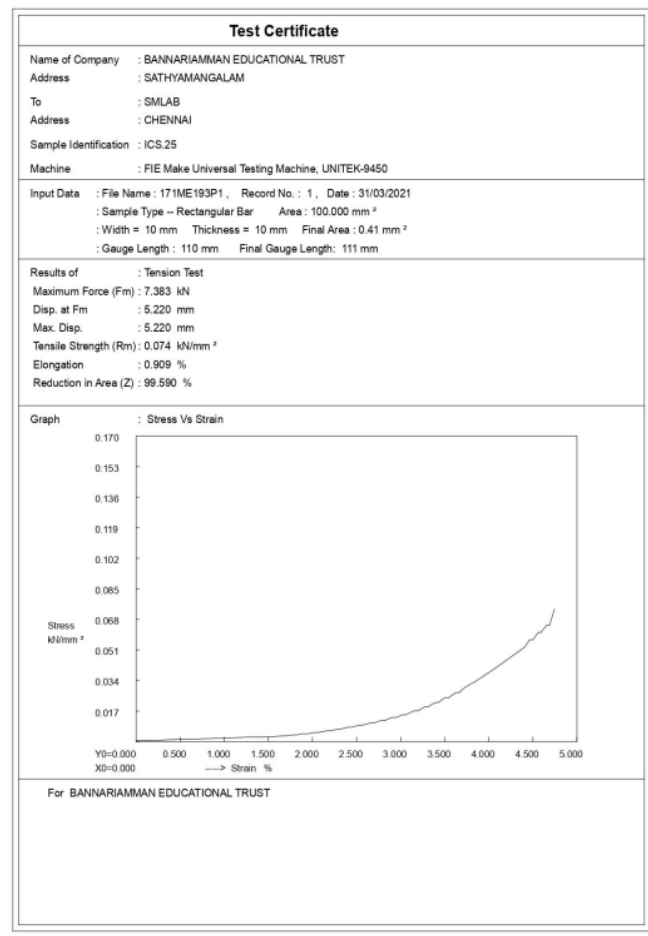

Figure 12. Stress vs Strain graph for specimen 2

The specimen is made in rectangular cross section structure after testing it have the 
maximum load or force of $7.383 \mathrm{kN}$, maximum displacement of $5.220 \mathrm{~mm}$, Tensile Strength of $0.074 \mathrm{kN} / \mathrm{mm} 2$ and elongation percentage of $0.909 \%$. The final area obtained is $0.41 \mathrm{~mm} 2$ and final gauge length is $111 \mathrm{~mm}$.

\section{Tensile Test Result for Specimen 3}

This specimen is made with feed rate of $4.80 \mathrm{~mm}$ per minute, voltage of $4 \mathrm{v}$ and precision voltage of $7 \mathrm{v}$ and current range at 110 to $150 \mathrm{amps}$. After the post processing the material is made into $10 \mathrm{~mm}$ length and thickness of $10 \mathrm{~mm}$ as per the testing standard of the machine. It is clamped into machine in the jaws and the load is given to the material. The load and displacement graph are carried out as shown in the figure 14. The stress and displacement are obtained in the graph as shown in the figure 15 and also stress vs strain curve graph is obtained as shown in the figure 16.

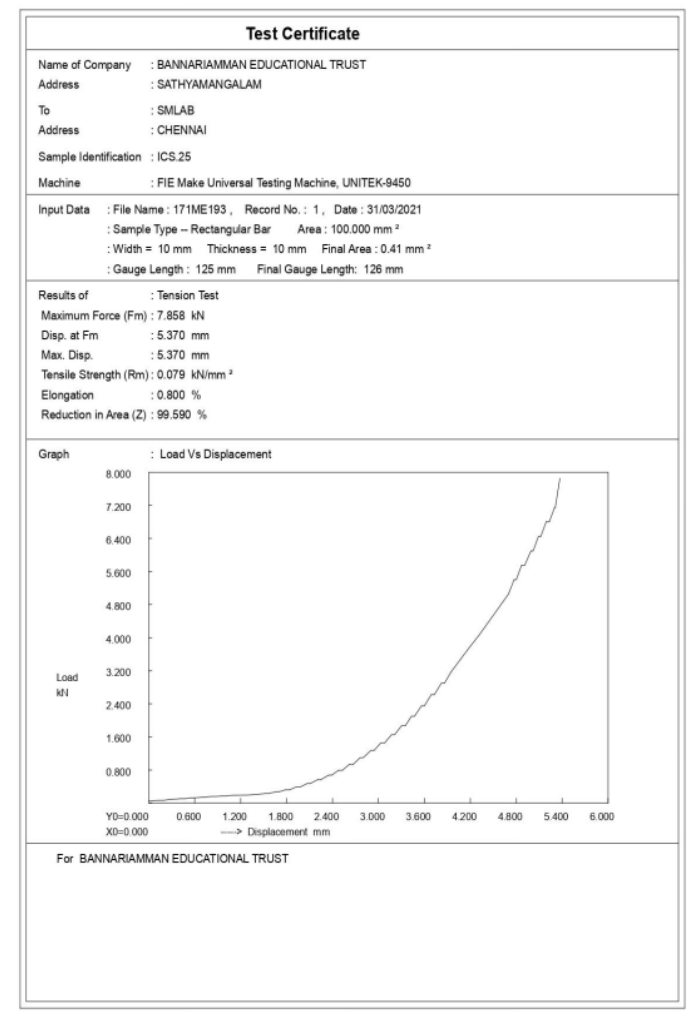

(a)

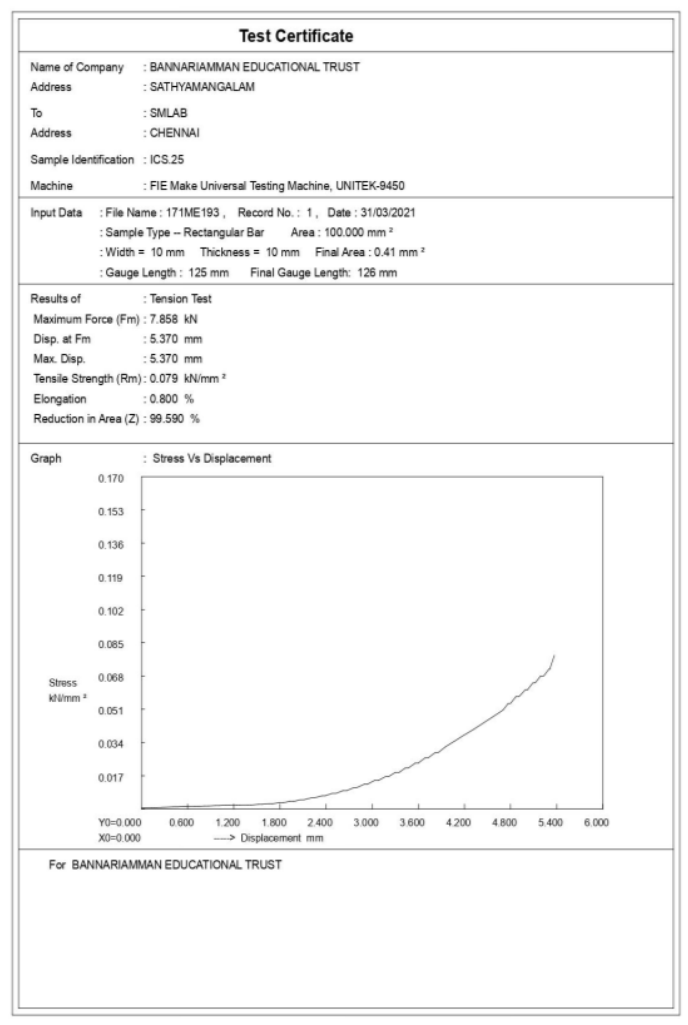

(b)

Figure 13. (a) Load vs Displacement graph for specimen 3, (b) Stress vs Displacement graph for specimen 3 


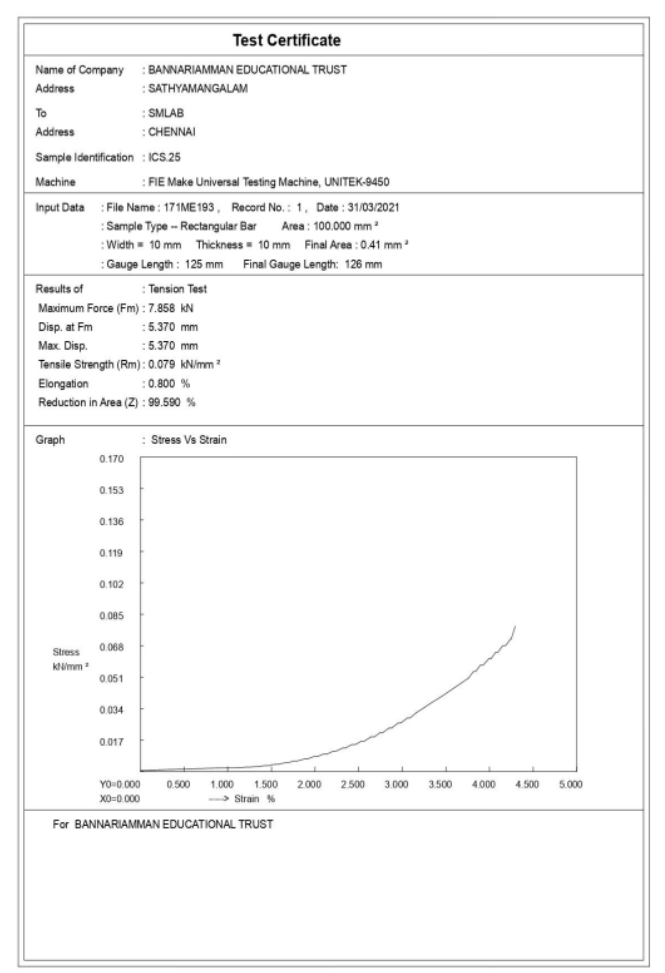

Figure 14. Stress vs Strain graph for specimen 3

The specimen is made in rectangular cross section structure after testing it have the maximum load or force of $7.858 \mathrm{kN}$, maximum displacement of $5.370 \mathrm{~mm}$, Tensile Strength of $0.079 \mathrm{kN} / \mathrm{mm} 2$ and elongation percentage of $0.800 \%$. The final area obtained is $0.41 \mathrm{~mm} 2$ and final gauge length is $126 \mathrm{~mm}$.

\section{Bead Geometry}

The physical characteristics of a weldment are bead geometry and penetration. The welding parameters appear to affect the bead geometry and penetration such as high arc- journey charge or low arc-strength normally produced poor fusion. For better bead width higher electrode feed range is necessary for making the bead flatter. The current and the voltage given to the machine and arc-travelling rate affect the intensity of penetration in the bead geometry. Shallow penetration obtained by longer arc-length and upward thrust generates when there was too small arc-period.

For calculating the bead geometry value and the error in the deposited material formula is given below the measured bead geometry $A m=2 w h / 3$ is calculated using this formula Where $A m$ is measured area $\left(\mathrm{mm}^{2}\right), w$ is Width $(\mathrm{mm}), h$ is Height $(\mathrm{mm})$ and the Predicated bead geometry $A=2 \pi V_{\mathrm{r}} d^{2} / 4 \mathrm{~V}_{\mathrm{t}}$ where the $p$ is Area of bead predicated $\left(\mathrm{mm}^{2}\right), V_{\mathrm{r}}$ is ER70S-6 Wire speed $(\mathrm{m} / \mathrm{min}), d$ is filler wire diameter $(\mathrm{mm}), V_{\mathrm{t}}$ is speed of torch in $(\mathrm{m} / \mathrm{min})$. The predicated value is tabulated in table 4 for the bead geometry analysis for the deposition of material.

\begin{tabular}{|l|l|l|l|l|l|l|l|}
\hline S. & Current & Wire & Torch & Width w & Height h & weld bead area $\left(\mathrm{mm}^{2}\right)$ & Error \\
\hline
\end{tabular}




\begin{tabular}{|c|c|c|c|c|c|c|c|c|}
\hline $\begin{array}{c}\mathbf{N} \\
\mathbf{0}\end{array}$ & $\mathbf{I}(\mathbf{a m p})$ & $\begin{array}{c}\text { speed } \\
\mathbf{V r} \\
(\mathbf{m} / \mathbf{m i n})\end{array}$ & $\begin{array}{c}\text { speed } \\
\mathbf{V t} \\
(\mathbf{m} / \mathbf{m i n})\end{array}$ & $\mathbf{( m m )}$ & $\mathbf{( m m )}$ & Measured & Predicted & \\
\hline 1 & 70 & 2.00 & 0.40 & 6.27 & 2.75 & 11.50 & 11.30 & 1.66 \\
\hline 2 & 70 & 2.00 & 1.09 & 3.30 & 1.70 & 3.74 & 4.15 & -10.92 \\
\hline 3 & 70 & 2.00 & 1.78 & 2.80 & 1.20 & 2.24 & 2.54 & -13.40 \\
\hline 4 & 110 & 3.00 & 0.70 & 6.38 & 2.50 & 10.63 & 10.34 & 2.80 \\
\hline 5 & 110 & 3.00 & 1.58 & 4.11 & 1.68 & 4.60 & 4.58 & 0.53 \\
\hline 6 & 110 & 3.00 & 2.45 & 3.20 & 1.30 & 2.77 & 2.95 & -6.47 \\
\hline 7 & 150 & 4.00 & 1.00 & 6.55 & 2.34 & 10.22 & 10.85 & -6.20 \\
\hline 8 & 150 & 4.00 & 2.00 & 4.48 & 1.65 & 4.93 & 5.43 & -10.10 \\
\hline 9 & 150 & 4.00 & 3.00 & 3.40 & 1.40 & 3.17 & 3.62 & -13.99 \\
\hline
\end{tabular}

\section{CONCLUSION}

Study on the bead geometry in wire arc additive manufacturing process is successfully completed by taking the samples based on the machine parameters by depositing the filler material in a layer-by-layer procedure with the help of MACH3 controller software for synchronized movement for all three axes. Based on literature study material deposition parameter and samples taken is identified in layer-by-layer deposition from which it is clearly inferred that the voltage ranges of 6 to 7 volts, ampere range of 65 to $125 \mathrm{amps}$ and feed rate of 2 to $3 \mathrm{~mm} / \mathrm{sec}$ suitable good bead geometry deposition is obtained. During the experimentation it is clearly identified that shielding gases plays a vital role in maintaining the quality of layer which is been deposited. After that a wall like product is made and gone for post processing also it is taken for tensile test for tensile strength of the material the tensile strength for various parameters material is between $0.074 \mathrm{kN} / \mathrm{mm} 2$ to $0.079 \mathrm{kN} / \mathrm{mm} 2$. The post processing time involved in wire arc additive manufacturing is comparatively higher than other metal printing process.

\section{REFERENCES}

Suryakumar S, Karunakaran KP, Bernard A, Chandrasekhar U, Raghavender N, Sharma D 2011. Weld bead modeling and process optimization in hybrid layered manufacturing. Computer-Aided Design, 43(4):331-44.

Tiago A.Rodrigues, V.Duarte, Julian A.Avila, Telmo G.Santos, R.M.Miranda, J.P.Oliveira, 2019. Wire and arc additive manufacturing of HSLA steel: Effect of thermal cycles on microstructure and mechanical properties, Additive Manufacturing, Vol 27:440450 .

Horgar, A., Fostervoll, H., Nyhus, B., Ren, X., Eriksson, M., \& Akselsen, O.M. 2018. Additive manufacturing using WAAM with AA5183 wire. Journal of Materials Processing Technology, 259: 68-74.

Adinarayanappa SM, Simhambhatla S 2014. Determination of process parameter for twin-wire weld-deposition based additive manufacturing. International Design Engineering Technical Conferences and Computers and Information in Engineering Conference, 46353, V004T06A003.

Marinelli G, Martina F, Ganguly S, Williams S 2020. Grain refinement in an unalloyed tantalum structure by combining wire+ arc additive manufacturing and vertical cold 
rolling. Additive Manufacturing, 32:101009.

Baby J, Amirthalingam M 2020. Microstructural development during wire arc additive manufacturing of copper-based components. Welding in the World, 64(2):395-405.

Ryan EM, Sabin TJ, Watts JF, Whiting MJ 2018. The influence of build parameters and wire batch on porosity of wire and arc additive manufactured aluminium alloy 2319 . Journal of Materials Processing Technology,262:577-84.

Wang T, Zhang Y, Wu Z, Shi C 2018. Microstructure and properties of die steel fabricated by WAAM using H13 wire. Vacuum, 149:185-9.

Cunningham CR, Wikshåland S, Xu F, Kemakolam N, Shokrani A, Dhokia V, Newman ST 2017. Cost modelling and sensitivity analysis of wire and arc additive manufacturing. Procedia Manufacturing, 11:650-7.

Sun R, Li L, Zhu Y, Guo W, Peng P, Cong B, Sun J, Che Z, Li B, Guo C, Liu L 2018. Microstructure, residual stress and tensile properties control of wire-arc additive manufactured 2319 aluminum alloy with laser shock peening. Journal of Alloys and Compounds, 747:255-65.

Yangfan W, Xizhang C, Chuanchu S 2019. Microstructure and mechanical properties of Inconel 625 fabricated by wire-arc additive manufacturing. Surface and Coatings Technology, 374:116-23.

Somashekara MA, Suryakumar S 2017. Studies on dissimilar twin-wire welddeposition for additive manufacturing applications. Transactions of the Indian Institute of Metals, 70(8):2123-35.

Wahsh LM, EIShater AE, Mansour AK, Hamdy FA, Turky MA, Azzam MO, Salem HG 2018. Parameter selection for wire arc additive manufacturing (WAAM) process. Proceedings of the Materials Science and Technology, 78-85.

Xu X, Ding J, Ganguly S, Diao C, Williams S 2019. Preliminary investigation of building strategies of maraging steel bulk material using wire+ arc additive manufacture. Journal of Materials Engineering and Performance, 28(2):594-600.

Williams SW, Martina F, Addison AC, Ding J, Pardal G, Colegrove P 2016. Wire+ arc additive manufacturing. Materials Science and Technology, 32(7):641-7.

Ravi G, Murugan N, Arulmani R. (2020). Microstructure and mechanical properties of Inconel-625 slab component fabricated by wire arc additive manufacturing. Materials Science and Technology, 36(16), 1785-1795.

Sun R, Li L, Zhu Y, Guo W, Peng P, Cong B, Sun J, Che Z, Li B, Guo C, Liu L 2018. Microstructure, residual stress and tensile properties control of wire-arc additive manufactured 2319 aluminum alloy with laser shock peening. Journal of Alloys and Compounds, 747:255-65.

S.W.Williams, F.Martina, A.C.Addision, J.Dig, G.pardal, P.Colegrove,2016. Wire Arc Additive Manufacturing, Materials Science and Technology,32:641-647.

Liberini M, Astarita A, Campatelli G, Scippa A, Montevecchi F, Venturini G, 
Durante M, Boccarusso L, Minutolo FM, Squillace A 2017. Selection of optimal process parameters for wire arc additive manufacturing. Procedia Cirp, 62:470-4.

Prado-Cerqueira JL, Diéguez JL, Camacho AM 2017. Preliminary development of a Wire and Arc Additive Manufacturing system (WAAM). Procedia Manufacturing, 13:895902. 